University of Wollongong

Research Online

Faculty of Engineering and Information

Faculty of Engineering and Information

Sciences - Papers: Part A

Sciences

$1-1-2012$

Recrystallisation behaviour of low carbon steel with and without addition of chromium

Azdiar A. Gazder

University of Wollongong, azdiar@uow.edu.au

Vladimir Bata

Monash University

Sujoy S. Hazra

University of Wollongong, ssh755@uow.edu.au

Elena V. Pereloma

University of Wollongong, elenap@uow.edu.au

Follow this and additional works at: https://ro.uow.edu.au/eispapers

Part of the Engineering Commons, and the Science and Technology Studies Commons

Research Online is the open access institutional repository for the University of Wollongong. For further information contact the UOW Library: research-pubs@uow.edu.au 


\title{
Recrystallisation behaviour of low carbon steel with and without addition of chromium
}

\begin{abstract}
The effects of $0.74 \mathrm{wt} \% \mathrm{Cr}$ addition on the recrystallisation kinetics of low carbon (LC) steel was investigated using Vickers hardness testing, optical metallography and Electron Back- Scattering Diffraction (EBSD). Compared to the unalloyed steel, $\mathrm{Cr}$ addition significantly delays the time for recrystallisation and increases the JMAK pre-exponential factor $(k)$ by an order of magnitude. During initial softening, EBSD returned similar orientations for nucleated and growing grain fractions in both steels. However with longer annealing times the micro-texture of recrystallised grains differs from their earlier counterparts. Overall, the effect of fine $\mathrm{Cr}$ carbides on grain boundary mobility in the LC-Cr steel causes variations in recrystallisation kinetics, grain morphology and micro-textures.
\end{abstract}

\section{Keywords}

carbon, steel, without, recrystallisation, addition, behaviour, chromium, low

\section{Disciplines}

Engineering | Science and Technology Studies

\section{Publication Details}

Gazder, A. A., Bata, V., Hazra, S. S. \& Pereloma, E. V. (2012). Recrystallisation behaviour of low carbon steel with and without addition of chromium. Materials Science Forum, 715-716 679-684. 


\title{
Recrystallisation Behaviour of Low Carbon Steel With and Without Addition of Chromium
}

\author{
Azdiar A. Gazder ${ }^{1, a}$, Vladimir Bata ${ }^{2}$, Sujoy S. Hazra ${ }^{1, b}$ and Elena V. \\ Pereloma ${ }^{1, c}$
}

\author{
${ }^{1}$ School of Mechanical, Materials and Mechatronic Engineering, University of Wollongong, \\ Wollongong, Australia \\ ${ }^{2}$ Previously with the Department of Materials Engineering, Monash University, Clayton, Australia \\ aazdiar@uow.edu.au, bssh755@uow.edu.au, celenap@uow.edu.au
}

Keywords: Low carbon steels, Cr addition, annealing, recrystallization, texture.

\begin{abstract}
The effects of $0.74 \mathrm{wt} \% \mathrm{Cr}$ addition on the recrystallisation kinetics of low carbon (LC) steel was investigated using Vickers hardness testing, optical metallography and Electron BackScattering Diffraction (EBSD). Compared to the unalloyed steel, $\mathrm{Cr}$ addition significantly delays the time for recrystallisation and increases the JMAK pre-exponential factor $(k)$ by an order of magnitude. During initial softening, EBSD returned similar orientations for nucleated and growing grain fractions in both steels. However with longer annealing times the micro-texture of recrystallised grains differs from their earlier counterparts. Overall, the effect of fine $\mathrm{Cr}$ carbides on grain boundary mobility in the LC-Cr steel causes variations in recrystallisation kinetics, grain morphology and micro-textures.
\end{abstract}

\section{Introduction}

Low carbon (LC) steels are subject to strain ageing either dynamically during production or statically during subsequent storage. In both cases ageing occurs due to the presence of carbon in solid solution and its interaction with dislocations [1]. Both ageing processes adversely affect the final properties of LC steels such as the strength-ductility balance, formability and surface quality. Consequently an approach to reduce or eliminate solute carbon from the matrix by alloying with strong carbide-forming elements such as chromium ( $\mathrm{Cr}$ ) has been suggested [2-4]. Although $\mathrm{Cr}$ addition has improved ageing behaviour in LC steels $[5,6]$ it is also necessary to consider the effects of such composition modification on overall alloy performance during all stages of processing. In this work we compare the recrystallisation processes in unalloyed LC steel with a $0.74 \mathrm{wt} \%$ Cr-containing LC steel.

\section{Experimental}

The compositions of the studied steels (commercial A06 and experimental Cr-alloyed steels hereafter referred to as LC and LC-Cr, respectively) are given in Table 1 . The steels were hot rolled followed by simulated coiling at $660^{\circ} \mathrm{C}$ and then cold rolled to $82 \%$ thickness reduction. Further processing details are given elsewhere [7]. Small samples $\left(20 \times 10 \times 0.5 \mathrm{~mm}^{3}\right)$ were cut from the strip and heat treated using a metal bath (a cylindrical alumina crucible filled with Al-Si eutectic) positioned inside a vertical tube furnace. The wire-suspended samples were immersed for different times at temperatures ranging from 565 to $670^{\circ} \mathrm{C}$ and then rapidly water quenched.

After heat treatment the samples were polished and characterised using Vickers microhardness and optical microscopy. Selected samples were examined using a JEOL 7001F field emission gun - 
scanning electron microscope equipped with a Nordlys-II camera and the Corona Fast Acquisition Electron Back-Scattering Diffraction (EBSD) system.

Table 1. Chemical composition of the LC steels [wt\%].

\begin{tabular}{c|c|c|c|c|c|c|c|c|c|c|c}
\hline Steel & $\mathrm{C}$ & $\mathrm{N}$ & $\mathrm{Mn}$ & $\mathrm{Al}$ & $\mathrm{S}$ & $\mathrm{P}$ & $\mathrm{Si}$ & $\mathrm{Ni}$ & $\mathbf{C r}$ & $\mathrm{Cu}$ & $\mathrm{Mo}$ \\
\hline LC* & $0.06 /$ & 0.0025 & $0.2 /$ & $0.035 /$ & $0.008 /$ & $-/$ & $-/$ & $0.02 /$ & \multirow{2}{*}{02} & $0.02 /$ & \\
& 0.07 & 0.0035 & 0.22 & 0.04 & 0.010 & 0.016 & 0.002 & 0.025 & & 0.025 & - \\
\hline LC-Cr & 0.064 & 0.0028 & 0.21 & 0.047 & 0.0045 & 0.0050 & 0.024 & 0.015 & $\mathbf{0 . 7 4}$ & 0.007 & 0.002 \\
\hline
\end{tabular}

* Legend: higher/lower

Misindexes and wild spikes were initially removed following which post-processing was undertaken using the Channel-5 software package. Low-angle boundaries (LAGBs) comprise misorientations between $2^{\circ}$ and $15^{\circ}$ while high-angle boundaries (HAGBs) extend from $15^{\circ}$ onwards. The application of $1^{\circ}$ as the average internal misorientation cut-off angle coupled with an in-house developed methodology separates the microstructure into deformed, recovered and softened fractions. Thereafter newly nucleated grains (which are a subset of the softened fraction) are defined as microscopic features with: (i) a lower limit of equivalent circle diameter (ECD) equal to three times the step size; (ii) an upper limit of ECD equal to the mean of the log-normal frequency distribution and; (iii) at least one HAGB. Consequently the growing grain elements comprise softened structures with sizes between the mean and maximum of the log-normal frequency distribution.

\section{Results and Discussion}

Using microhardness data the softening kinetics were determined as shown in Fig. 1. It is clear that $\mathrm{Cr}$ addition delays recrystallisation and significantly alters the pre-exponential factor $(k)$ of the JMAK fit by an order of magnitude. While the fraction softened estimated via EBSD is close to JMAK predictions in the case of LC-Cr steel, the faster recrystallisation kinetics in LC steel returned larger variations. The latter suggests increasing the average internal misorientation cut-off angle beyond $20 \%$ softening at present heating rates for LC steel.

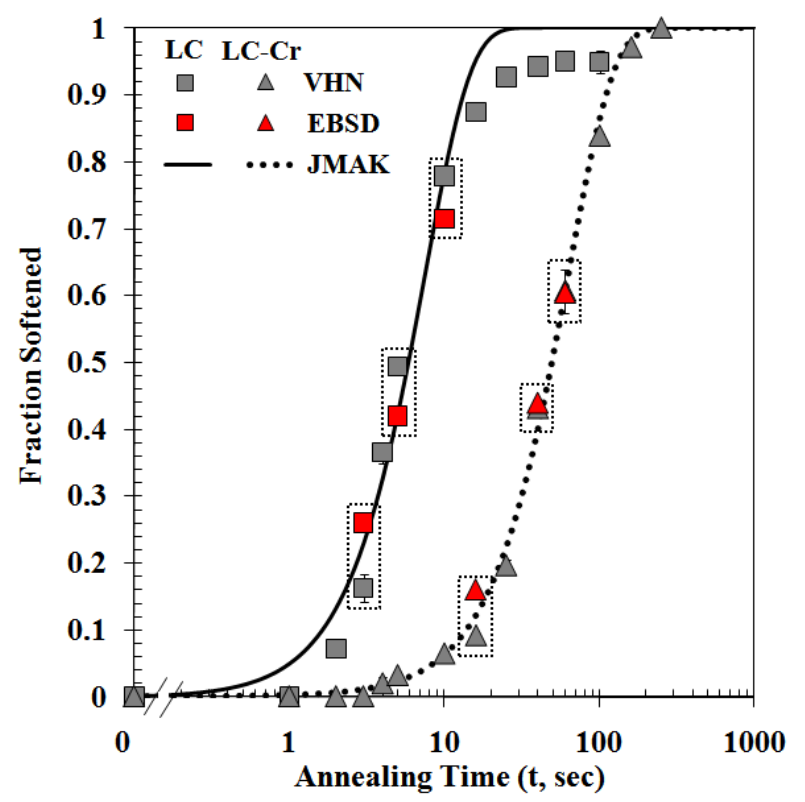

Figure 1. The effect of annealing time on the fraction softened for LC and LC-Cr steels.

LC: $\quad k=0.051 \pm 0.017, n=1.47 \pm 0.184$

LC-Cr: $k=0.002 \pm 4 \mathrm{E}-4, \quad n=1.49 \pm 0.058$

Figs. 2 and 3 show the evolution of recrystallisation at $630^{\circ} \mathrm{C}$ in both steels via optical and EBSD maps. Nucleation of new grains occurs heterogeneously in longitudinally aligned clusters with more equiaxed recrystallised morphologies in LC as compared to LC-Cr steel. Deformed grain boundaries and triple junctions are the preferred nucleation sites during the initial stages of recrystallisation. With greater annealing times nuclei also form in grain interiors on deformation defects such as in-grain shear bands. Similar to the annealing of WR Cr-alloyed LC steels [8], the 
significant numbers of relatively coarse cementite and alloy carbides aligned parallel to the RD (Fig. 2 and [6]) become nucleation sites during later stages of recrystallisation in both steels. Although the aspect ratio of softened grains in LC steel reduces with greater annealing time, it increases slightly in LC-Cr steel (Table 2). The elongated morphology of softened grains in LC-Cr steel could be ascribed to the coarse and fine $\mathrm{Cr}$-alloyed carbides which restrict grain growth in the TD via pinning [6,7]. Compared to $\mathrm{Fe}_{3} \mathrm{C}$ precipitates, $\mathrm{Cr}$-carbides are more stable against dissolution and coarsening at $630^{\circ} \mathrm{C}$ and thus remain more effective in influencing the morphology and growth rates of nucleated grains (Table 2).

a

$\mathrm{b}$
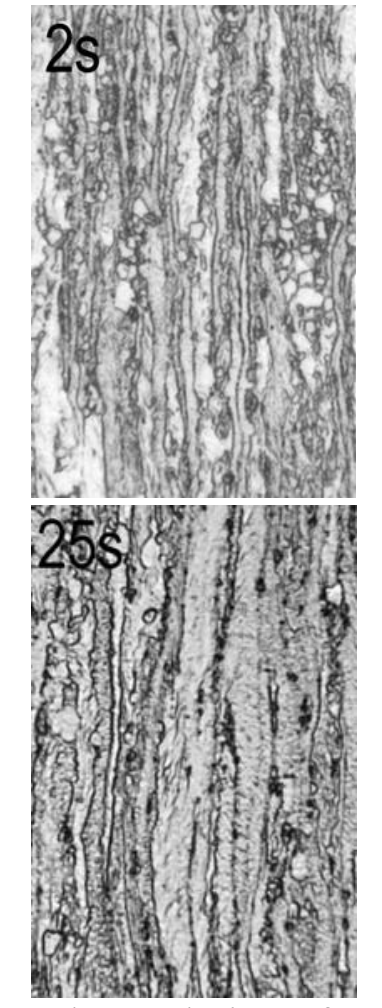
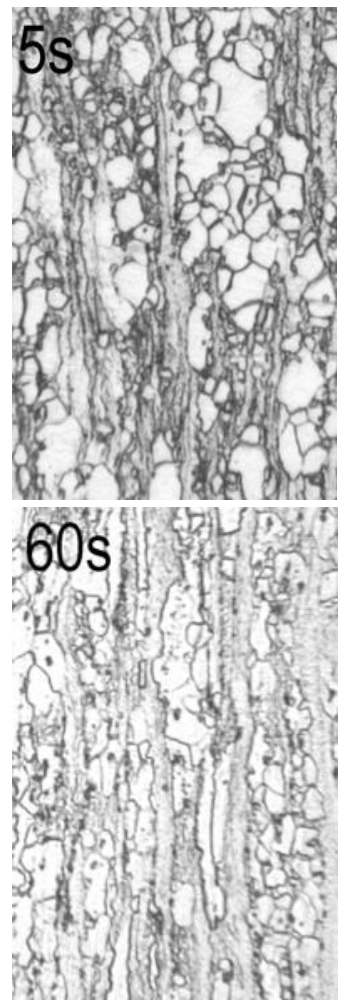
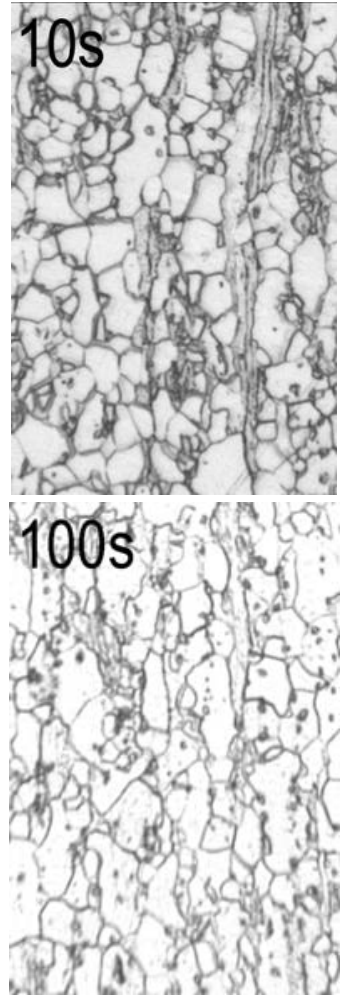
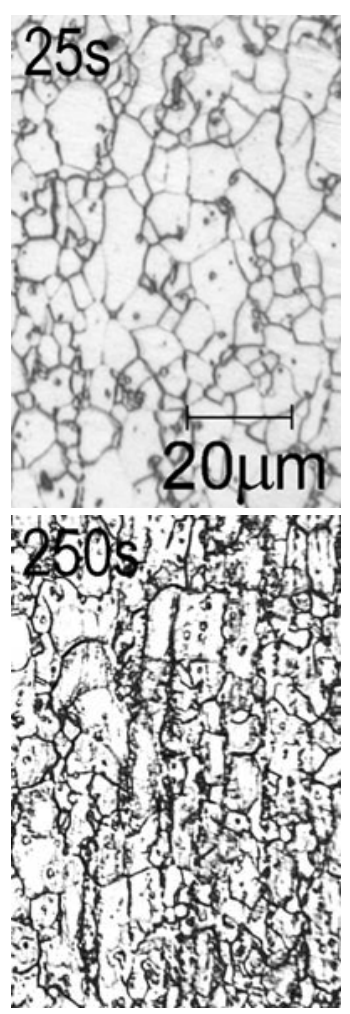

Figure 2. The evolution of recrystallisation at $630^{\circ} \mathrm{C}$ in LC (a) and LC-Cr (b) steels. Cold rolling direction is vertical.

In both steels the boundary misorientation of recovered grains shows a slight increase in HAGBs compared to deformed grains after $3 \mathrm{~s}$ (LC) and 16s (LC-Cr) annealing (Fig. 4). In contrast to LC steel, the misorientation profile of the nucleated grains in LC-Cr steel has a greater asymmetry of distribution with higher positive skewness and kurtosis values indicating a bias towards lower class intervals and a greater relative peakedness. In the case of growing grains, the opposite trend is seen with positive skewness and kurtosis values almost double for LC compared to LC-Cr steels. Consequently these variations result in a flatter profile for the growing grains in the latter steel.

${ }_{2}=45^{\circ}$ ODF sections after $3 \mathrm{~s}$ (LC) and 16s (LC-Cr) annealing are shown in Figs. 5(a-d) and (fi) for the deformed, recovered, nucleated and growing grain subsets of the EBSD maps (Figs. 3(a, d)). The deformed grains in both steels are similar to their recovered counterparts with: (i) a strong

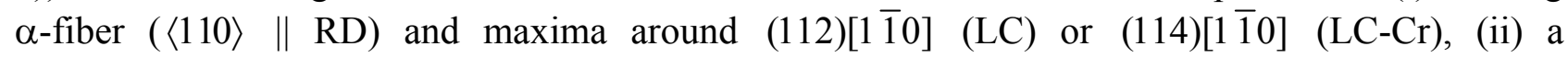
comparatively weaker $\gamma$-fiber ( $\langle 111\rangle \| \mathrm{ND}$ ) with maxima around $\{111\}\langle 112\rangle$ (LC) and $\{111\}\langle 110\rangle$ (LC-Cr) and, (iii) a strong rotated cube $\{001\}\langle 110\rangle$ component. It is noted here that ODF intensities between steels are indirectly comparable at similar softening fractions as magnification and step size were constant during mapping. In contrast to the $\{113\}\langle 471\rangle$ orientation developing during the recrystallisation of $95 \%$ CR ULC steel [11], the spread of the $\alpha$-fiber in the deformed and recovered fractions includes this orientation in both steels and is associated with a secondary fiber running parallel to RD from $\{111\}\langle 112\rangle$ to $(001)[1 \overline{2} 0]$. In both steels the ODFs of the nucleated (Figs. 5(c, 
h)) and growing grains (Figs. 5(d, i)) show the $\gamma$-fiber with peaks near $\{111\}\langle 112\rangle$ and weaker texture components along the $\alpha$-fiber.

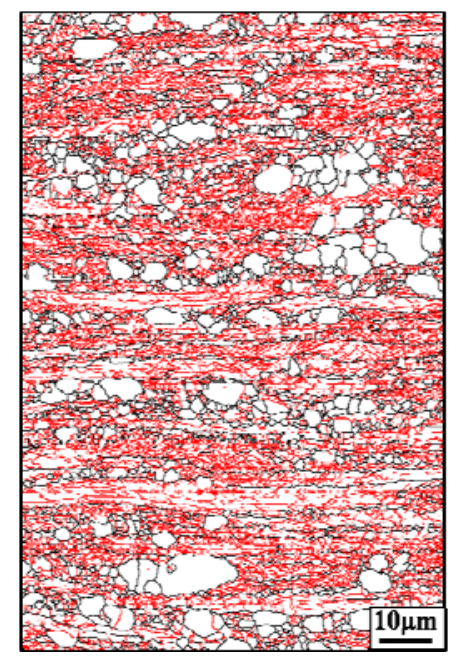

a

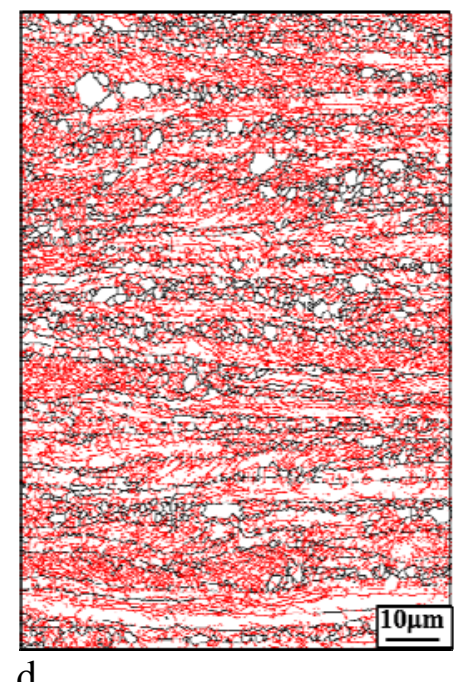

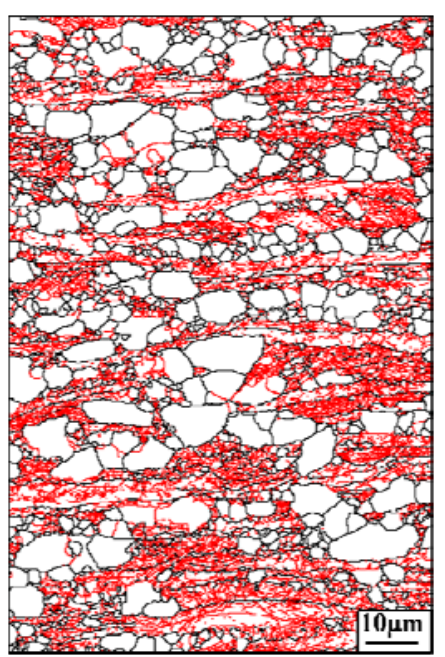

b

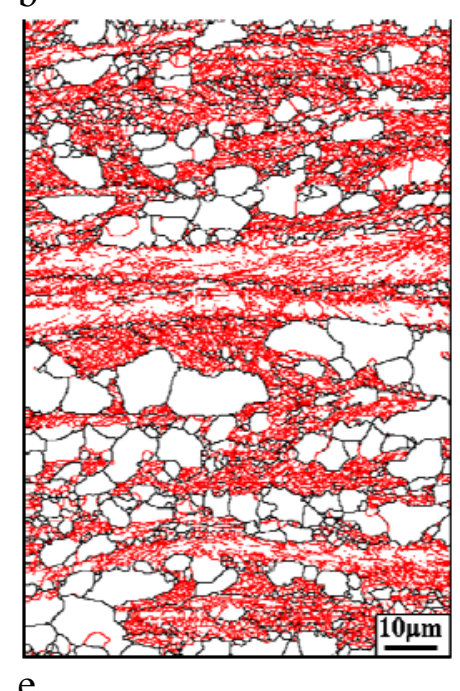

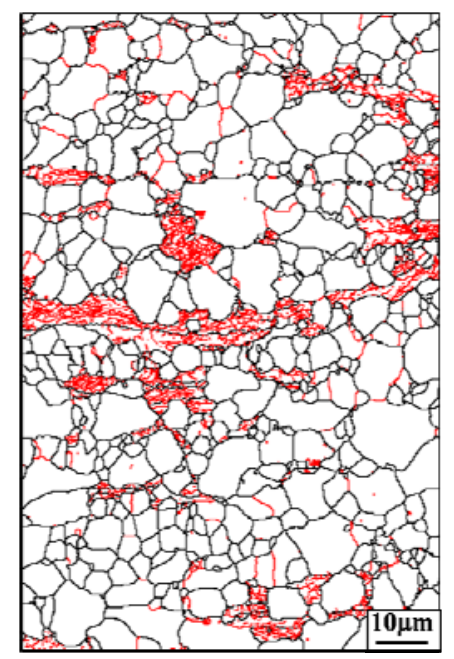

C

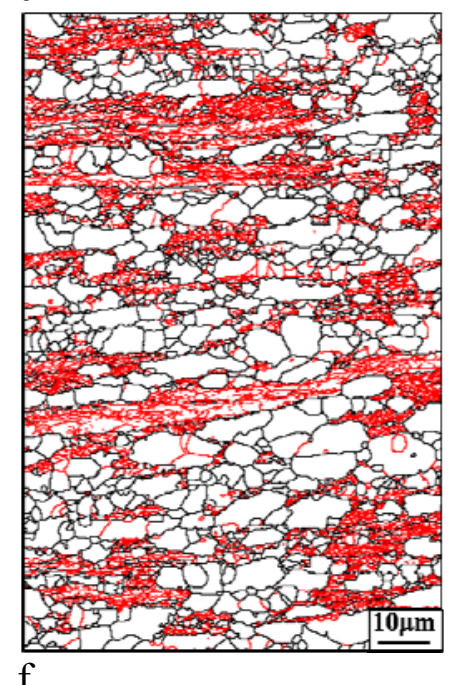

Figure 3. Partially recrystallised microstructures in (a-c) LC and (d-f) LC-Cr steels after (a) 3, (b) 5, (c), 10, (d) 16 , (e) 40 and (f) 60 s isothermal annealing at $630^{\circ} \mathrm{C}$. (red $=$ LAGBs, black $=$ HAGBs). TD view, $\mathrm{RD}=$ horizontal.

Table 2. EBSD returned microstructure parameters for LC and LC-Cr steels.

\begin{tabular}{|c|c|c|c|c|c|c|c|}
\hline \multirow{2}{*}{\multicolumn{2}{|c|}{$\begin{array}{c}\text { Microstructural } \\
\text { Parameters }\end{array}$}} & \multicolumn{3}{|c|}{ LC } & \multicolumn{3}{|c|}{$\mathrm{LC}-\mathrm{Cr}$} \\
\hline & & $3 \mathrm{~s}$ & $5 s$ & $10 \mathrm{~s}$ & $16 \mathrm{~s}$ & $40 \mathrm{~s}$ & $60 \mathrm{~s}$ \\
\hline \multirow{2}{*}{\multicolumn{2}{|c|}{$\begin{array}{l}\text { Deformed, }[\%] \\
\text { Recovered }[\%]\end{array}$}} & 48 & 43 & 11 & 50 & 42.5 & 29 \\
\hline & & 26 & 15 & 17.5 & 34 & 13.5 & 10.5 \\
\hline & 4.5 & 2.7 & 0.9 & 4.4 & 1.9 & 0.9 \\
\hline \multicolumn{2}{|c|}{ Growing Grains, $[\%]$} & 21.5 & 39.3 & 70.6 & 11.6 & 42.1 & 59.6 \\
\hline \multicolumn{2}{|c|}{ Total Recrystallised, [\%] } & 26 & 42 & 71.5 & 16 & 44 & 60.5 \\
\hline \multirow{2}{*}{$\begin{array}{l}* \text { LAGBs }+ \\
\text { HAGBs, }[\mu \mathrm{m}]\end{array}$} & ECD & $0.89 \pm 0.74$ & $0.98 \pm 0.89$ & $2.24 \pm 2.16$ & $0.85 \pm 0.66$ & $0.90 \pm 0.85$ & $1.21 \pm 1.17$ \\
\hline & AR & $2.17 \pm 1.18$ & $2.16 \pm 1.13$ & $1.88 \pm 0.82$ & $1.95 \pm 0.94$ & $2.06 \pm 0.89$ & $2.12 \pm 0.99$ \\
\hline \multirow{2}{*}{ HAGBs, $[\mu \mathrm{m}]$} & ECD & $1.72 \pm 1.89$ & $2.11 \pm 2.06$ & $3.67 \pm 2.83$ & $1.53 \pm 1.92$ & $2.04 \pm 2.26$ & $2.41 \pm 2.07$ \\
\hline & AR & $2.88 \pm 2.39$ & $2.67 \pm 2.16$ & $1.86 \pm 0.87$ & $2.54 \pm 2.04$ & $2.53 \pm 1.63$ & $2.59 \pm 1.92$ \\
\hline
\end{tabular}

* Legend: $\mathrm{ECD}=$ equivalent circle diameter; $\mathrm{AR}=$ aspect ratio. 
While the $\gamma$-fiber of nucleated grains in both steels are of similar strengths, the $\{111\}\langle 112\rangle$ peaks of growing grains in LC-Cr steel are weaker and have a larger orientation spread. The similarity of texture components between the newly nucleated and growing grains in both steels supports the oriented nucleation mechanism during recrystallisation. However with greater annealing, all recrystallised grains (nucleated and growing) in both steels (Figs. 5(e, j)) show: (i) a small weakening of the $\{111\}\langle 112\rangle$ peaks in favour of $\{111\}\langle 110\rangle$-type orientations, (ii) a slight orientation spread towards $\{554\}\langle 225\rangle$ and, (iii) persistently weak (114)[1 $\overline{1} 0],\{113\}\langle 471\rangle$ and rotated cube orientations. Observations (ii) and (iii) have been reported to occur during late stages of recrystallisation [11].

It is also noted that while the intensities and spread of the $\{111\}\langle 112\rangle$ and $\{111\}\langle 110\rangle$ orientations are comparable in LC steel (Fig. 5(e)), the latter orientation is slightly stronger and has a smaller spread in LC-Cr steel (Fig. 5(j)). Although such variations may arise from map-specific local micro-texture effects, it could also be ascribed to the influence of delayed recrystallisation via carbide pinning and the consequent retention of deformation substructures for longer annealing times in LC-Cr steel.
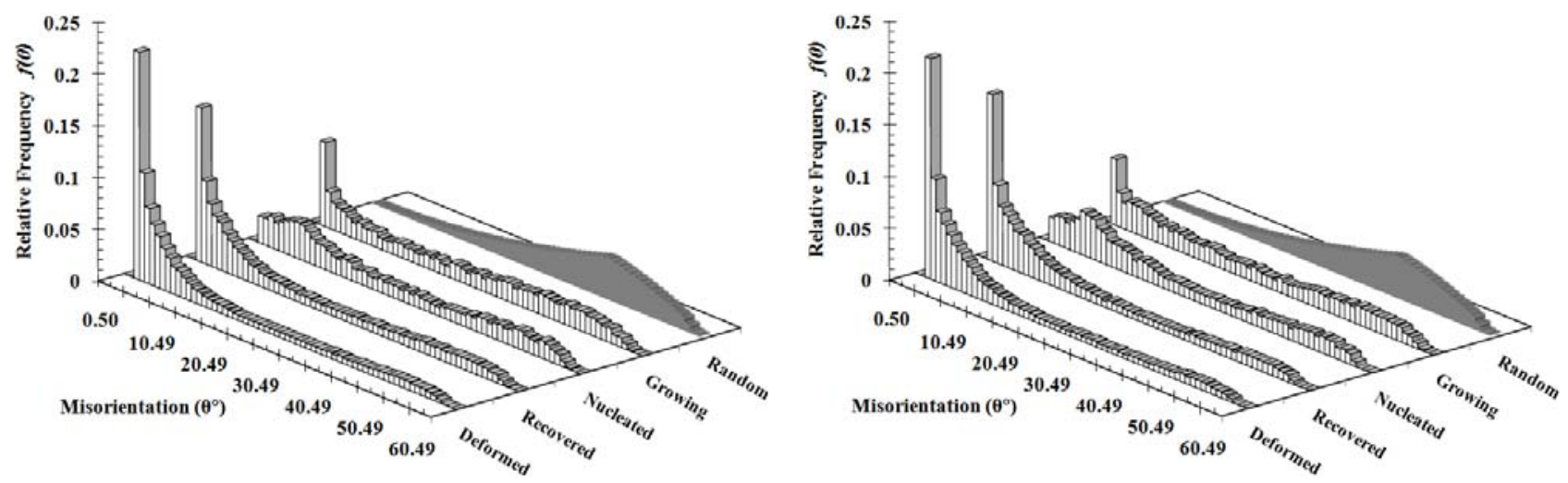

b

Figure 4. Misorientation histograms of the deformed, recovered, nucleated and growing recrystallised grains after isothermal annealing at $630^{\circ} \mathrm{C}$ for (a) $3 \mathrm{~s}, \mathrm{LC}$ steel and (b) $16 \mathrm{~s}, \mathrm{LC}-\mathrm{Cr}$ steel.

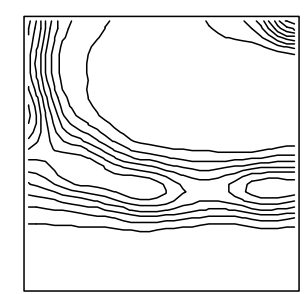

a

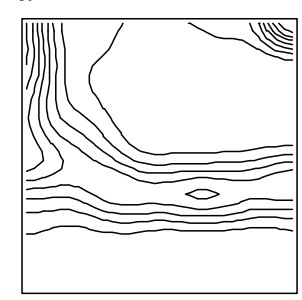

$\mathrm{f}$

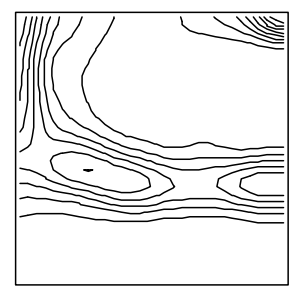

$\mathrm{b}$

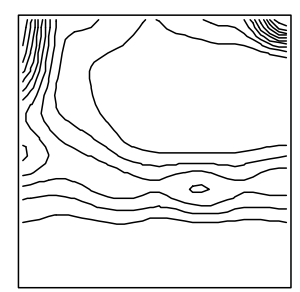

g

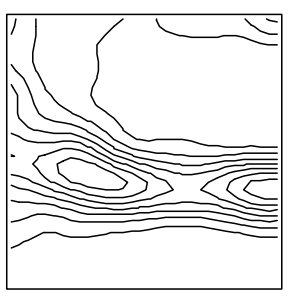

C

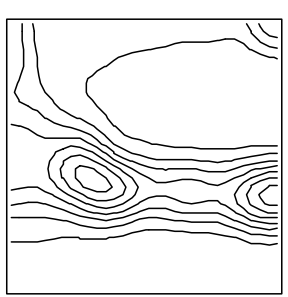

$\mathrm{h}$

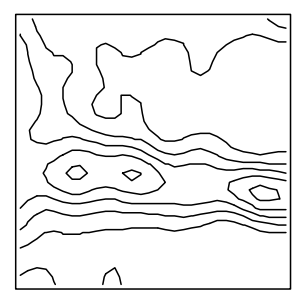

d

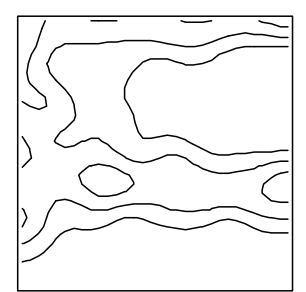

i

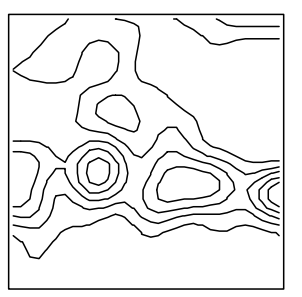

e

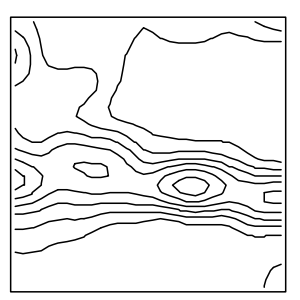

j

Figure 5. $\quad 2=45^{\circ}$ ODF sections of the (a, f) deformed, $(\mathrm{b}, \mathrm{g})$ recovered, $(\mathrm{c}, \mathrm{h})$ nucleated and $(\mathrm{d}, \mathrm{i})$ growing grains after (a-d) $3 \mathrm{~s}$, LC steel and (f-i) 16s, LC-Cr steel. Figs. (e) and (j) are of all recrystallised grains after $10 \mathrm{~s}, \mathrm{LC}$ steel and $60 \mathrm{~s}, \mathrm{LC}-\mathrm{Cr}$ steel respectively. Contour levels: $1 \times$. 
In both steels the newly nucleated and growing grains are essentially of similar orientation during initial softening. Even during the predominantly growth-mediated stages of recrystallisation (corresponding to longer annealing times), the reducing area fractions of newly nucleated grains consist of orientations similar to the earliest stages of softening. Such texture resemblance throughout the recrystallisation and growth processes supports the oriented nucleation mechanism $[9,10]$. While selective growth has been observed during late stages of recrystallisation in $95 \% \mathrm{CR}$ ULC steels $[11,12]$ due to the strong $\alpha$-fiber in the cold worked state, the $82 \%$ CR reduction in the present case may not be sufficient to activate this mechanism.

Whereas differences in recrystallisation behaviour between the two steels could be associated with nucleation at carbides and the effect of fine $\mathrm{Cr}$ carbides on grain boundary mobility via pinning, the micro-texture evolution with longer annealing times also shows changes in crystallographic orientation and intensity. From predominantly $\{111\}\langle 112\rangle$ textures during initial softening, a shift favouring equivalent (LC) or slightly stronger (LC-Cr) $\{111\}\langle 110\rangle$-type orientations occurs during grain growth at longer annealing times. Thus along with the crystallographic orientation of newly nucleated grains, subsequent growth characteristics also play an important role in overall texture development.

\section{Summary}

Studies of the recrystallisation behaviour in cold rolled low carbon steel with and without $\mathrm{Cr}$ addition have shown that $\mathrm{Cr}$ not only retards the kinetics of recrystallisation but also affects the texture and morphology of recrystallised grains. The variations in micro-textures between LC and LC-Cr steels could be ascribed to carbide pinning via retention of deformation substructures for longer annealing times in case of the latter.

\section{Acknowledgement}

This work was supported by the Australian Research Council DP 0663511.

\section{References}

[1] A.H. Cottrell, B.A. Bilby: Proc. Phys. Soc. Vol. 62A (1949) p. 49.

[2] M.R. Barnett: ISIJ Int., 38 (1998), p.78.

[3] A.O. Humphreys, D.S. Liu, M.R. Toroghinezhad and J.J. Jonas: ISIJ Int. Vol. 42 (2002), Supplement, p. S52.

[4] I.B. Timokhina, A.I. Nosenkov, A.O. Humphreys, J.J. Jonas and E.V. Pereloma: ISIJ Int. Vol. 44 (2004), p.717.

[5] M.R. Barnett in: Proc. Materials 98, edited by M. Ferry, Wollongong University Press, Wollongong, (1998), p.167.

[6] E. Pereloma, V. Bata, R. Scott, R. Smith: Mater. Sci. Forum Vol. 539-543 (2007), p. 4214.

[7] E.V. Pereloma, V. Bata, R.I. Scott and R.M. Smith: Mater. Sci. Eng A, DOI 10.1016/j.msea.2009.12.040, available online 07/01/2010.

[8] I.B. Timokhina, J.J. Jonas, E.V. Pereloma: ISIJ Int., Vol. 45 (2005)

[9] W.B. Hutchinson, in Mater. Sci. Forum. Switzerland: Trans.Tech; (1994), p. 1917.

[10] R.K. Ray, J.J. Jona, R.E. Hook: Int. Mater. Rev. Vol. 39 (1994), p. 129.

[11] K. Verbeken, L. Kestens,J.J. Jonas: Scripta Mater. Vol. 48 (2003), p. 1457.

[12] L. Kestens, Y. Houbaert, in: Thermomechanical Processing of Steel, edited by S. Yue, E. EsSadiqi and J.J. Jonas Met. Soc., Canada (2000), p. 411. 